\title{
Development of a Low Cost Bioprocess for Endotoxin Production by Bacillus thuringiensis var israelensis Intended for Biological Control of Aedes aegypti
}

\author{
Carlos Ricardo Soccol ${ }^{1}$, Teresinha E. V. Pollom ${ }^{2}$, Ricardo Cancio Fendrich ${ }^{1}$, Fernando \\ Alberto Prochmann ${ }^{1}$, Radijiskumar Mohan ${ }^{1}$, Marita Maciel Moreira Blaskowski ${ }^{3}$, André \\ Luiz de Almeida Melo ${ }^{1}$, Cláudio Jose Barros de Carvalho ${ }^{2}$ and Vanete Thomaz-Soccol ${ }^{3 *}$ \\ ${ }^{I}$ Divisão de Engenharia de Bioprocessos e Biotecnologia; Departamento de Engenharia Química; Centro \\ Politécnico; Universidade Federal do Paraná; 81531-970; Curitiba - PR - Brasil. ${ }^{2}$ Setor de Ciências Biológicas; \\ Universidade Federal do Paraná; 81531-970; Curitiba - PR - Brasil. ${ }^{3}$ Departamento de Patologia Básica; Setor de \\ Ciências Biológicas; Universidade Federal do Paraná; 81531-970; Curitiba - PR - Brasil
}

\begin{abstract}
Aedes aegypti is the vector of Dengue disease, responsible for 20,000 deaths/year worldwide. Bacillus thuringiensis var israelensis -Bti releases selective and effective toxins (crystal proteins) against A. aegypti larvae. We present a low cost bioprocess for toxin production, accomplished by a selected Brazilian strain Bti (BR-LPBO1) and employment of low cost substrates. Soybean meal and sugarcane molasses lead to high toxic effectiveness after $2 L$ bioreactor fermentation $\left(L D_{50}=26 \mathrm{ng} / \mathrm{mL}\right)$, near to the reference strain IPS82 $\left(L D_{50}=17.3 \mathrm{ng} / \mathrm{mL}\right)$. The pH ranged between 5.8 and 7.0 during the exponential growth period and between 7.0 and 8.4 during the stationary phase, with low activity. Thus, control of foam and pH 7.0 were started and proved to be crucial for high activity. It was verified that the fermentation could be discontinued after 20 hours, when the highest activity was present.
\end{abstract}

Key words: Biopesticide, BTI, Dengue Fever Disease, Soybean meal, Sugarcane molasses

\section{INTRODUCTION}

According to the World Health Organization (WHO, 2008), with the exception of European countries, between 50 and 100 million people worldwide are infected with the dengue virus yearly in 100 countries. Approximately 550,000 patients require hospitalization, and around 20,000 deaths are reported annually. Extensive outbreaks of dengue fever have followed the spread of the insect vector over the African, Asiatic and American continents.

The Secretariat of Health Surveillance of the Ministry of Health (SVS/MS) in Brazil recorded 787,726 suspected dengue cases, 4,137 confirmed cases of Dengue Hemorrhagic Fever (DHF) and the occurrence of 223 DHF deaths in 2008 from January to November. Furthermore, 17,477 cases of dengue were reported with clinical complications that resulted in 225 deaths (Source:

\footnotetext{
* Author for correspondence: vasoccol@ufpr.br
} 
Report of the Epidemiological Dengue, January to November 2008).

In Brazil, the official vector of dengue is the $A$. aegypti mosquito. In 1976, socio-environmental conditions allowed the spread of the mosquito and the disease. There is no technical evidence that mosquito eradication is possible in the short or medium term, and therefore the appropriate local solution for the control of dengue is to develop permanent control programs at low operational costs. In urbanized areas, A. aegypti is the most epidemiologically important Culicidae family member, not only because of its role in transmission of the dengue fever virus but also because of the possibility of the urban cycle of yellow fever by this mosquito, which was eradicated in Brazil in 1942 (Codeco et al., 2004).

The microorganism $B t i$ is demonstrably effective against the $A$. aegypti larvae, killing them specifically with natural toxins, even at low levels of exposure (Obeta and Okafor, 1984; Pollom, 2003; Poopathi and Kumar, 2003; Prabakaran et al., 2008, Prabakaran and Hoti, 2008, 2008b). The toxins have a crystalline structure and are released into the medium after sporulation. They are ingested by the larva and produce pores in the intestinal wall, which then breaks down. The spores invade the larva body, resulting in widespread infection, muscle paralysis and drowning (Thomas and Eilar, 1983).

In endemic areas, prevention efforts and control programs for this disease are affected by the development of resistance of the insect vector to chemical insecticides, and by the increasing costs of these programs (Macoris et al., 2003). Furthermore, the non-selective mode of action of chemical insecticides affects non-target organisms, including several animal and vegetal species. Accumulation of these toxins in the food chain is highly hazardous to humans. Environmental contamination is an important factor, highlighting the need for selective agents that can be used for the biological control of insects that present a public health concern (Helgen et al., 1988; Pierce et al., 1989).

Chemical control has been the main strategy for controlling A. aegypti, and in Brazil, Temephos has been constantly used for that purpose since 1986 (Macoris et al., 2003). Spot anti-larval treatment is the starting point for accurate control, and low transmission levels can only be maintained with periodic, complete coverage of areas infested with vector. Current control programs for A. aegypti demand a large field staff and have high operational costs. Due to the large infested area, Brazil faces significant difficulties in control among municipalities and regions (Martins and Castiñeiras, 2005). Due to the high rate of insect spot creation and replacement, as well as the many possibilities for dispersion as a result of higher population mobility, it is certain that chemical control will never be by itself a method for $A$. aegypti eradication, or even for acceptable levels of control (Regis et al., 2008).

A bioinsecticide with high specificity, easy environmental degradation and low production costs could eliminate the ecological, economic and health impacts of chemical compounds used for control (Brar et al., 2006). However, bioinsecticide production has not yet resulted in high sales levels throughout the world. New products and formulations are being developed for commercialization (Hynes and Boyetchko, 2006). Parameters of fermentation and toxin production are particularly important for optimum product yield. The evaluation of various substrates is also an important factor, including the potential exploitation of agricultural products and agribusiness waste (Prabakaran and Balaraman, 2006).

Various researchers have explored alternatives to the preparation of several less expensive culture media for $B t i$ biopesticide production. Often, locally available, cost-effective substrates have been used and have been shown to achieve comparable or better results than those obtained using conventional medium.

Prabakaran and Balaraman (2006) attempted to develop a medium based on raw materials including soybean flour (Glycine max), groundnut cake powder (Arachis hypogea), and wheat bran extract (Triticum aestivum) in a 100-L fermentor. Prabakaran et al. (2008) made a cost-effective medium with coconut water, which is a raw material that is abundantly available as a waste product from the coconut oil industry. Yezza et al. (2006) conducted the bioconversion of industrial wastewater and wastewater sludge into a biopesticide in a pilot fermentor.

Poopathi and Kumar (2003) used potato, common sugar, and Bengal gram substrates. Poopathi and Abidha (2007, 2008) made feather extract and feather powder, and explored the possibility of degrading chicken feathers discarded from the poultry processing industry. Obeta and Okafor (1984) assessed the production of insecticidal 
properties using shake flasks, making five variations of the basal medium by adding different types of legume seeds, including groundnut cake (Arachis hypogea), cow pea (Vigna unguiculata, white variety), cow pea (Vigna unguiculata, black variety), soya beans (Glycine soja), and bambara beans (Voandzeia subterranean).

Ghribi et al. (2007) applied a new medium composed of only starch, soya bean and diluted sea water. Özkan et al. (2003) studied various nutritional and cultural parameters influencing delta-endotoxin synthesis and found that, among carbon sources, inulin, dextrin, maltose, lactose, sucrose, whey and glycerol were all stimulatory, while glucose, starch and some molasses were suppressive.

This work sought the screening for Brazilian strains and then apply those with demonstrated toxic effectiveness. Biomass of strains were produced with locally abundant low-cost substrates at a larger scale than the commonly used laboratory Erlenmeyer flasks, and were effective in the medium composition used during cultivation in a $2 \mathrm{~L}$ bioreactor.

\section{MATERIALS AND METHODS}

\section{Bacillus thuringiensis var israelensis strains}

The strains IPS82 and IPS88 from the Pasteur Institute Paris and the Pasteur Institute Burkina Faso, respectively, were used for reference. A total of twelve strains isolated in Brazil (BR-LPB01, BRLPB02， BR-LPB03， BR-LPB04， BR-LPB07， BRLPB08, BR-LPB11， BR-LPB14， BR-LPB15， BRLPB16, BR-LPB17, BR-LPB18) were evaluated for selective production of toxin. These strains belong to the bank of strains at the Bioprocess Engineering and Biotechnology Division of the Federal University of Parana in Brazil. All strains were grown in $50 \mathrm{~mL}$ Nutrient Broth Difco ${ }^{\circledR}$ in Erlenmeyer flasks, for 48 hours, $120 \mathrm{rpm}$ and $28^{\circ} \mathrm{C}$, with $\mathrm{pH} 6.8$. Aliquots of $3 \mathrm{~mL}$ plus $1 \mathrm{~mL}$ of glycerin were frozen at $-12^{\circ} \mathrm{C}$ to serve as starting cultures for fermentation. Five flasks were frozen with $5 \%$ glycerin in liquid nitrogen to preserve the strain.

\section{Aedes aegypti larvae}

Eggs of A. aegypti were obtained from three origins: the Pasteur Institute Paris, the Pasteur Institute Burkina Faso and a local strain from the northern region of Parana State, Brazil. They were incubated in dechlorinated water for formation and maintenance of the colonies used to produce the fourth instar (L4) larvae for bioassays. The adult mosquitoes were kept in screen-lined wooden cubic cages, and eggs were collected on dry filter paper after they were laid near a container of dechlorinated water. Adult insects were fed with sugar solution. For stimulation of oviposition, blood repasts were conducted using previously anesthetized mice. The eggs were incubated at $28^{\circ} \mathrm{C}$ in order to obtain larvae for use in bioassays and to replace adults. The larvae were incubated in flasks at $28^{\circ} \mathrm{C}$ with dechlorinated water and fed everyday with feed for fish (Alcon®).

\section{Bioassays}

The assays were based on the mortality of $A$. aegypti larvae exposed to various dilutions of the fermented medium. Bioassays were performed to determine the most resistant of the A. aegypti larvae against the Bti reference strain IPS82, with exposure to freeze-dried and sugarcane molasses fermented broth. The selected IPP A. aegypti larvae were used in subsequent bioassays to measure the larvicidal activity of the fermented broth. These assays were performed in plastic bottles with dechlorinated water, each with 20 larvae. The larvae were in the $4^{\text {th }}$ instar stage of development (L4) because L4 larvae are more resistant to the toxin and because more homogeneous samples could be obtained. Progressive dilutions of fermented broth were added to these bottles. All assays were performed at least once, all in triplicate. To validate this technique, three control flasks with no toxin were always prepared. The material was incubated at $25^{\circ} \mathrm{C}$ for 24 hours.

\section{Toxic-effective strain selection}

Aliquots from 14 strains were originally used to inoculate tubes $\left(10 \mathrm{~mL}, 28^{\circ} \mathrm{C}, 48 \mathrm{~h}, \mathrm{pH} 6.8\right)$ and then Erlenmeyer flasks $\left(50 \mathrm{~mL}, 28^{\circ} \mathrm{C}, 48 \mathrm{~h}, \mathrm{pH} 6.8\right.$, $120 \mathrm{rpm}$ ). The medium used was composed of nutrient broth (meat extract $3 \mathrm{~g} / \mathrm{L}$ and peptone 5 $\mathrm{g} / \mathrm{L})$. An inoculum rate of $10 \%$ was used for all passages. Fermented medium dilutions of $1 / 100$, $1 / 1,000,1 / 10,000$ and 1/100,000 were evaluated in bioassays.

\section{Production in a $2 \mathrm{~L}$ bioreactor}

To evaluate bacterium performance at a larger scale and under conditions of component depletion in the cultivation medium, the BR-LPB01 strain 
was grown in a $2 \mathrm{~L}$ bench bioreactor, using $1 \mathrm{~L}$ of cultivation broth at an initial $\mathrm{pH}$ of 7 , with agitation at $450 \mathrm{rpm}$ and $1.5 \mathrm{vvm}$ aeration, over 28 hours at $30^{\circ} \mathrm{C}$ (Santa et al., 2005). The composition of the medium used in $2 \mathrm{~L}$ bioreactor fermentation was $(\mathrm{g} / \mathrm{L})$ : Hsu and $\mathrm{Wu}(2002)$ Soya Protein, 45.0; Glucose 30.0; $\mathrm{K}_{2} \mathrm{HPO}_{4}, \quad$ 5.0; $\mathrm{KH}_{2} \mathrm{PO}_{4}, 5.0 ; \mathrm{MnSO}_{4} .4 \mathrm{H}_{2} \mathrm{O}, 0.03 ; \mathrm{MgSO}_{4} .7 \mathrm{H}_{2} \mathrm{O}$, $0.05 ; \quad \mathrm{CaCl}_{2} .7 \mathrm{H}_{2} \mathrm{O}, \quad 0.05 ; \quad \mathrm{FeSO}_{4} .7 \mathrm{H}_{2} \mathrm{O}, 0.01$; $\mathrm{NaNH}_{4} \mathrm{HPO}_{4} .4 \mathrm{H}_{2} \mathrm{O}, 1.5$.

The inoculum was prepared in Erlenmeyer flasks with $100 \mathrm{~mL}$ of Nutrient Broth, maintained at $28^{\circ} \mathrm{C}$ for 15 hours with $120 \mathrm{rpm}$ agitation. Preinoculum was prepared in a test tube with $10 \mathrm{~mL}$ of medium.

The second fermentation was run with the same cultivation medium, but with $\mathrm{pH}$ maintained at 7 by automatically controlled peristaltic pumps with $\mathrm{H}_{2} \mathrm{SO}_{4}$ and $\mathrm{NaOH}(1 \mathrm{M})$ solutions. The foam formation control was carried out with polypropyleneglycol.

The last product tested was obtained from a culture that utilized an altered fermentation medium. The herein suggested medium was based on the previous recipe, but glucose was replaced by sugarcane molasses, and soya protein was replaced by soybean meal in equivalent concentrations. In all fermentation runs, samples were collected every 2 hours and evaluated in bioassays.

\section{Preliminary Economic Evaluation}

Since the adapted medium was demonstrated to be effective, a preliminary economic evaluation was performed using local and current substrate quotations. The current currency conversion $(1 \mathrm{USD}=1.861$ BRL - Fri, 28 Aug 2009 13:52:19
GMT - Google Finance) was taken into account. Three different media were compared to the proposed (g/L): (i) Hsu and $\mathrm{Wu}$ (2002) (Soya Protein, 45.0; Glucose, 30.0; $\mathrm{K}_{2} \mathrm{HPO}_{4}, \quad$ 5.0; $\mathrm{KH}_{2} \mathrm{PO}_{4}, 5.0 ; \mathrm{MnSO}_{4} .4 \mathrm{H}_{2} \mathrm{O}, 0.03 ; \mathrm{MgSO}_{4} .7 \mathrm{H}_{2} \mathrm{O}$, $0.05 ; \quad \mathrm{CaCl}_{2} .7 \mathrm{H}_{2} \mathrm{O}, \quad 0.05 ; \quad \mathrm{FeSO}_{4} .7 \mathrm{H}_{2} \mathrm{O}, 0.01$; $\mathrm{NaNH}_{4} \mathrm{HPO}_{4} .4 \mathrm{H}_{2} \mathrm{O}$, 1.5); (ii) Luria Bertani conventional medium (peptone, 10.0; yeast extract, 5.0; sodium chloride 10.0); and (iii) NYSM conventional medium (glucose, 10.0; peptone, 5.0; yeast extract, 3.0; yeast extract, 0.5; $\mathrm{NaCl}, 5.0, \mathrm{~K}_{2} \mathrm{HPO}_{4}, 10.0$ ).

\section{RESULTS}

The Aedes aegypti fourth instar larvae IPP was chosen because of its high resistance to the Bacillus thuringiensis var israelensis reference strain (IPS82), as shown in Table 1. This strain presented the highest $\mathrm{LD}_{50}$ values. The highest level of larvae production was obtained after 4 days of hatching eggs in water. Adults were obtained in 6 days, and new oviposition occurred in 9 days. In the bioassays used for Bti strain selection, strains IPS82, IPS88 and BR-LPB01 showed great larvicidal activity (Table 2). The fermented products of these strains resulted in $100 \%$ mortality at all dilutions evaluated. Among the 12 strains isolated from Brazilian soil, only strain BR-LPB01 showed 100\% activity. For this reason, it was used in the subsequent studies. The wide variability of activity between the strains was probably due to the fact that they are Brazilian variants isolated from nature and therefore have great potential for production optimization through changes in culture parameters.

Table 1 - Aedes aegypti larvae $50 \%$ lethal doses $\left(\mathrm{LD}_{50}\right)$ by Bacillus thuringiensis var israelensis.

\begin{tabular}{ccc} 
Bioassay & LD $_{\mathbf{5 0}}(\mathbf{n g} / \mathbf{m L})$ & B. thuringiensis \\
Ae.aegypti strains & B. thuringiensis IPS82 (Freeze Dried) & BR-LPB01 (Sugarcane molasses broth) \\
\hline IPP & $17,3(14,82-19,78)$ & $26(23,42-28,58)$ \\
Burkina Faso & $2,9(0,44-5,36)$ & $3,6(1,12-6,08)$ \\
Apucarana - Brazil & $13(10,52-15,48)$ & $17,3(14,82-19,78)$ \\
\hline
\end{tabular}

Values between parenthesis $-95 \%$ confidence interval. 
Table 2 - Bioassay results: Bacillus thuringiensis var israelensis toxic effectiveness

\begin{tabular}{lcccc}
\multicolumn{1}{c}{ Larvae mortality (\%) Strains } & \multicolumn{3}{c}{ Dilutions } \\
\cline { 2 - 5 } & $\mathbf{1 / 1 0 0}$ & $\mathbf{1 / 1 , 0 0 0}$ & $\mathbf{1 / 1 0 , 0 0 0}$ & $\mathbf{1 / 1 0 0 , 0 0 0}$ \\
\hline IPS82; IPS88; BR-LPB01 & 100 & 100 & 100 & 100 \\
BR-LPB14 & 50 & 30 & 0 & 0 \\
BR-LPB02 & 30 & 0 & 0 & 0 \\
BR-LPB03; BR-LPB07; BR-LPB11; BR-PB16; & 10 & 0 & 0 & 0 \\
BR-LPB04; BR-LPB08; BR-LPB15; BR-LPB17; BR-LPB18; & 0 & 0 & 0 & 0 \\
Control & 0 & 0 & 0 & 0 \\
\hline
\end{tabular}

The first fermentation in a bench scale bioreactor resulted in a product without larvicidal activity. Foaming and $\mathrm{pH}$ controls were employed to resolve the problem. As shown in Figure 1, the second fermentation using the $\mathrm{Hsu}$ and $\mathrm{Wu}$ medium and Bti BR-LPB01 produced high activity. The dilution estimated at $1 / 100,000$ surprisingly presented $100 \%$ larvae mortality. This dilution was expected to be associated with scale expansion and testing of new parameters, and therefore the evaluated dilutions did produce interesting results.

To determine the actual effectiveness of the product, the fermentation sample collected after 28 hours was subjected to a new bioassay. This sample showed an activity of $100 \%$ until $1 / 400,000$ dilution and decreased only at a dilution of $1 / 1,000,000$. However it still presented a mortality rate of $50 \%$ at a dilution of $1 / 1,200,000$ (Fig. 2).

The product obtained from fermentation in substituted medium was subjected to more complete bioassays, evaluating the collected material at dilutions between 1/200,000 and $1 / 1,800,000$. Some results showed high larvicidal activity, as shown in Figure 3.

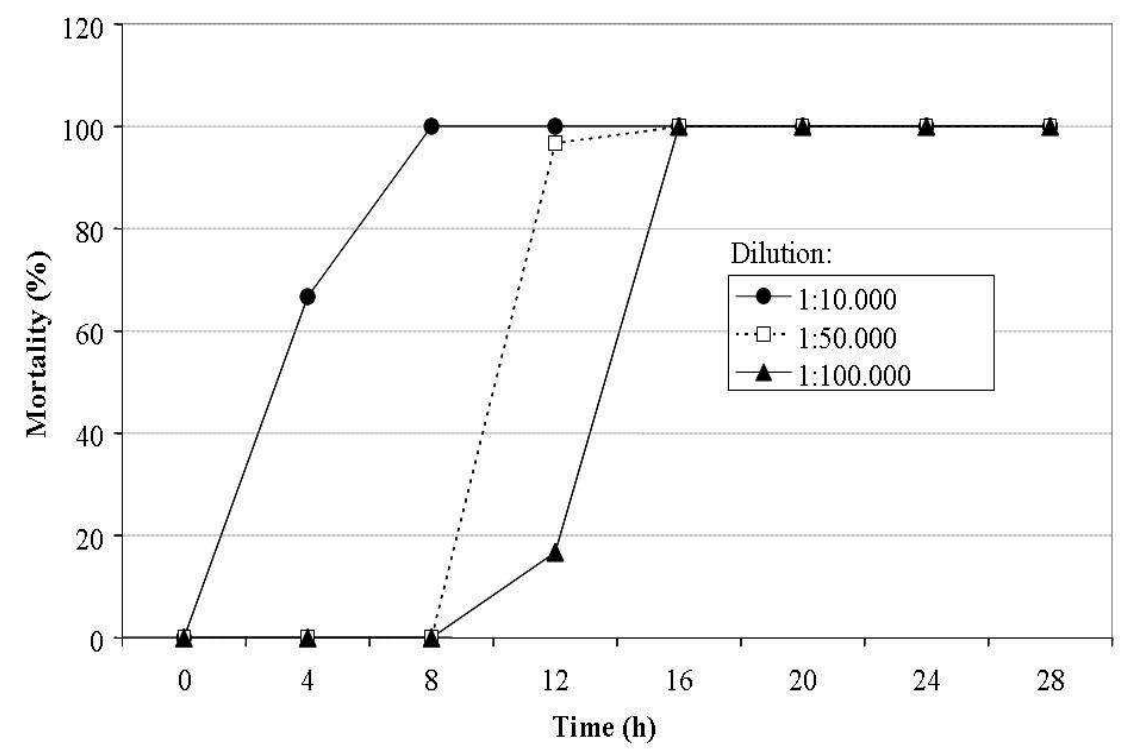

Figure 1 - Bioassay results of product relative to time samples in culture. Samples were obtained using Hsu and Wu suggested medium in a bench bioreactor (Bti BR-LPB01). 


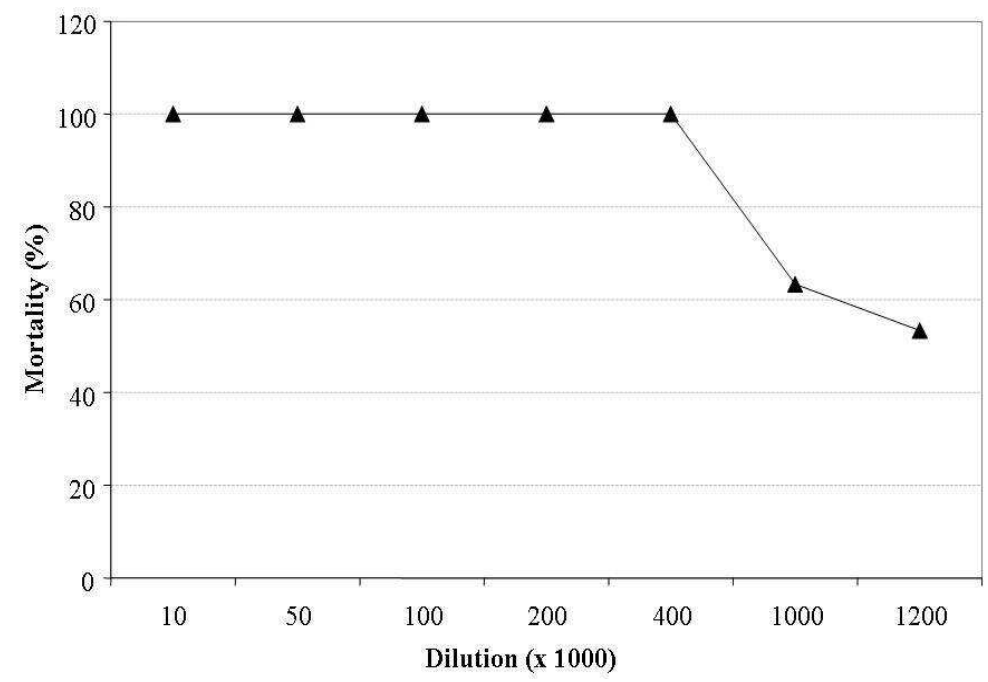

Figure 2 - Bioassay results of product obtained using the Hsu and $\mathrm{Wu}$ suggested medium in bench bioreactor (sample 28h). Toxic efficiency was verified at higher dilutions (Bti BRLPB01).

The two fermentation results were similar. The samples collected at hour 28 from the second fermentation showed just over $50 \%$ mortality at a dilution of $1 / 1,200,000$. The samples from hour 20 of the third fermentation showed almost identical activity, but by hour 28 , this activity was reduced to less than 20\% (Fig. 2 and Fig. 3).
The highest evaluated dilution of $1 / 1,800,000$ maintained a peak mortality of $30 \%$. It is important to note that the dilution of $1 / 400,000$ resulted in almost total mortality in samples taken after 20 hours, and it therefore became clear that the fermentation could be discontinued after this period, when the culture had the highest level of activity.

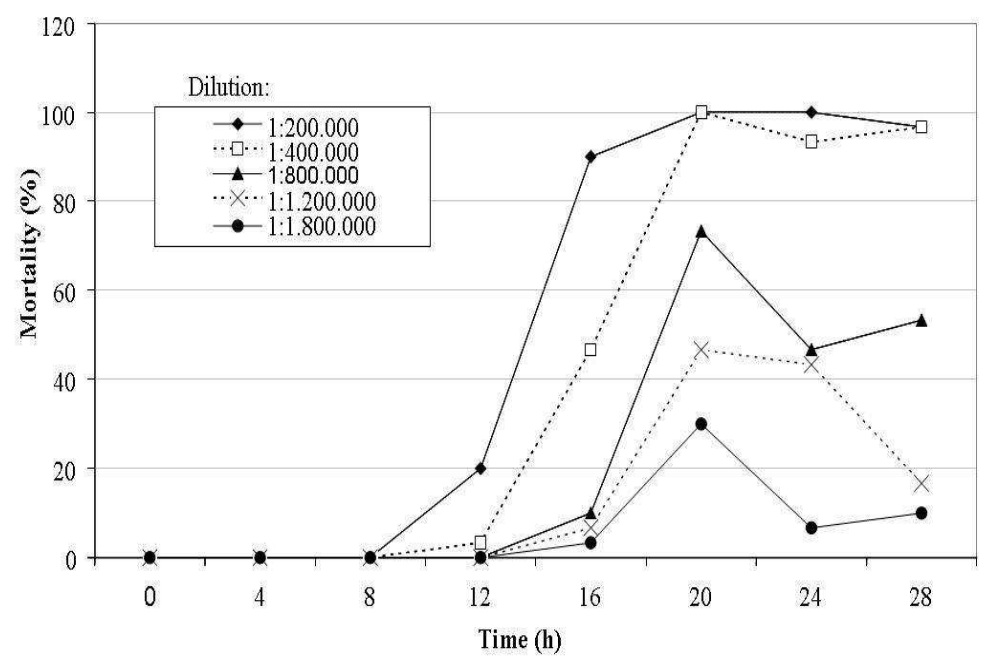

Figure 3 - Bioassay results of product relative to time samples obtained with substituted medium in bench bioreactor (Bti BR-LPB01). 


\section{DISCUSSION}

Increasing the scale of a fermentation process is an important step in bioprocess development. When working at the laboratory scale, such as in test tubes or in Erlenmeyer flasks, excellent results can be obtained. However, conversion of the process to a higher scale often does not produce the same results. This is a great challenge due to the difficulty of assessing which factors affect the process during the scaled up cultivation. Therefore, the fermentation processes conducted on a large scale may result in lower productivity than that obtained at the laboratory scale. It is well known that the microorganisms in a large-scale bioreactor are exposed to several physical, chemical and nutritional perturbations that are different from those grown in Erlenmeyer flasks. Variables that have been studied in the cultivation of Bti that affect toxin production include $\mathrm{pH}$, oxygen concentration and stirring shear stress (Hsu and $\mathrm{Wu}, 2002$ ).

In this work, the scale-up of the fermentation process was performed using the same media that were implemented at the laboratory scale, since they demonstrated high larvicidal activity in our preliminary study. However, the first fermentation product obtained did not cause mortality of L4 larvae. Variables such as oxygen rate and $\mathrm{pH}$ of the medium were then evaluated. It was found that the fermentation process resulted in great oscillation of $\mathrm{pH}$ during the lag phase of bacterial growth, with a change from the initial $\mathrm{pH}$ of 6.8 to a $\mathrm{pH}$ of 8.4. According to Hsu and $\mathrm{Wu}$ (2002), the number of bacterial cells and the concentration of toxin at $\mathrm{pH} 8.4$ are much lower than that at $\mathrm{pH}$ 7.0. If the $\mathrm{pH}$ can be maintained at $\mathrm{pH} 7.0 \pm 0.3$ throughout the culture in a large bioreactor, the growth of microorganisms will be similar to that in a small bioreactor at a controlled $\mathrm{pH}$ of 7.0.

In the culture of Bti, the toxin is associated with biomass production. The effects of changes in $\mathrm{pH}$ at exponential and stationary stages of growth were investigated. All cultures were kept at $\mathrm{pH} 7.0$ as a default cultivation condition before $\mathrm{pH}$ change. The control of $\mathrm{pH}$ was achieved by the addition of acid and base. The $\mathrm{pH}$ ranged between 5.8 and 7.0 during exponential growth and between 7.0 and 8.4 during the stationary phase. Therefore, $\mathrm{NaOH}$ and $\mathrm{H}_{2} \mathrm{SO}_{4}$ solutions were added respectively during exponential growth and stationary stage. Metabolic acids were probably excreted into the environment during exponential growth. An optimum stirring speed is essential in large scale fermentation in order to prevent cell disruption and $\mathrm{pH}$ perturbation. Variation of fermentation $\mathrm{pH}$ leads to a decrease in biomass and product concentration.

For carbon and nitrogen sources during bioreactor fermentation, we used the same components that had been previously used during Erlenmeyer flask fermentation. We found that the strain Bti-BRLPB01 showed high growth in the implemented medium with the replaced carbon and nitrogen sources. Comparison of the results obtained from A. aegypti larvae mortality revealed that the percentage of mortality reached $100 \%$ in the $1 / 400,000$ dilution and $75 \%$ in the $1 / 800,000$ dilution for the alternative medium that we developed, while in the commercial medium at the same dilution, the mortality rate was only $60 \%$.

Larvae were slightly more resistant in all bioassays using sugarcane molasses fermented broth with $B t i$ BR-LPB01, compared to reference strain IPS82 (Table 1). Previously published studies report $\mathrm{LD}_{50}$ values of biopesticides for this $A$. aegypti strain. Crickmore et al. (1995), Regis et al. (2001), and Poopathi and Kumar (2003) reported $\mathrm{LD}_{50}$ values of $10(8-12) \mathrm{ng} / \mathrm{ml}, 1-5 \mathrm{ng} / \mathrm{ml}$, and 1.63 $(1.42-1.87) \mathrm{ng} / \mathrm{mL}$ (48 $\mathrm{h}$ exposure), respectively. Macoris et al. (2003) reported values of $8 \mathrm{ng} / \mathrm{mL}$ and $10 \mathrm{ng} / \mathrm{mL}$ for the chemical pesticides Temephos and Fenitrothion, respectively.

These results demonstrate that it is feasible to replace sources of carbon and nitrogen in the commercial media by Brazilian agricultural substrates produced in large quantities, without loss of efficiency in terms of toxin production, and with an equivalent result of $A$. aegypti larvae death. High rates of A. aegypti L4 larvae mortality were obtained at both laboratory and semi-pilot scales, in Erlenmeyer flasks and bench bioreactors, respectively.

When comparing the mosquito larvae mortality rate obtained using the medium that we developed based on the results reported by $\mathrm{Hsu}$ and $\mathrm{Wu}$ (2002), we found that our product is more efficient at the same levels of growth broth dilutions. Our product had $100 \%$ larvae mortality in 17 hours, while the Hsu and $\mathrm{Wu}$ (2002) required a contact time of 24 hours in order to achieve the same efficiency. We emphasize that the composition of the medium described by $\mathrm{Hsu}$ and $\mathrm{Wu}$ (2002) used commercial glucose as a carbon source, while ours used molasses. 
Table 3 includes a revised cost comparison for biomass production based on current Brazilian quotations (August, 2009). A preliminary economic study shows that it is possible to achieve a reasonable production cost of Bti using the medium herein proposed. The proposed medium was found to be approximately $34 \%$ cheaper than the medium tested by Hsu and $\mathrm{Wu}$ (2002), with biomass production of 17.89 grams. With respect to the conventional media, Luria Bertani and NYSM, our medium was $10 \%$ and $40 \%$ cheaper, respectively.

Comparing the cost / kilogram of biomass makes our medium more economically favorable than when comparing the cost based on the cost / liter. It means the cost of the medium is around $41 \%$, $32 \%$ and $45 \%$ lesser than $\mathrm{Hsu}$ and $\mathrm{Wu}$, Luria Bertani and NYSM, respectively. It was considered the maximum theoretical biomass production of 15.0 and 18.0 grams / liter, for Luria Bertani and NYSM conventional media, respectively, considering the total conversion of initial carbon and nitrogen sources into biomass. Relative discount does not vary according to currency conversion, only in case of quotation changes.

Table 3 - Preliminary economic evaluation.

\begin{tabular}{cccc}
\hline Costs $^{*}$ & USD/L of medium & $\begin{array}{c}\text { Biomass } \\
\text { production X }(\mathbf{g X} / \mathbf{L})\end{array}$ & $\begin{array}{c}\text { USD } \\
\mathbf{1 0 0 0 g X}\end{array}$ \\
\hline Proposed & 1.836 & 19.77 & 92.88 \\
Hsu and Wu (2002) & 2.802 & 17.89 & 156.63 \\
Luria Bertani & 2.044 & $15.00^{* *}$ & 136.24 \\
NYSM & 3.057 & $18.00^{* *}$ & 169.84 \\
\hline
\end{tabular}

*Currency conversion (1 USD = 1.861 BRL - Fri, 28 Aug 2009 13:52:19 GMT - Google Finance).

** Theoretical values considering the total conversion of initial carbon and nitrogen sources into biomass.

Future studies will focus on partial or total removal of added minerals in the proposed medium of reference, Tryptose Phosphate, taking into account the fact that the molasses is rich in minerals. Studies are still needed to incorporate drying of this novel bioproduct by means of spray or freeze drying. The development of different formulations (liquid, powder, tablets), as well as the stability of these formulations at different temperatures and humidity levels and in different packaging must all be conducted. These factors are closely related to the final development of this technology and will facilitate its transfer to the productive sector. Future tests may include determination of the toxin production by Bacillus thuringiensis var israelensis in pilot bioreactors (10 and 100L) and semi-industrial vessels (1.000L).

This work demonstrates the technical and economic feasibility of the production of an insecticide highly specific to Culicidae larvae. This product is organic, biodegradable because of its protein composition, and has a low production cost due to the employment of low-cost substrates. The replacement of commercial formulations of media with Brazilian agricultural products and byproducts will reduce the cost of the cultivation medium and is an emerging alternative for employment of these materials in order to increase their assessed value.

The acquired product showed activity at high dilution levels, which is of extreme importance because of the aquatic environment in which mosquito reproduction occurs. Further studies seeking to optimize the parameters of the procedure and the formulation should certainly proceed and will lead to improvement of a more efficient product.

\section{RESUMO}

A dengue é transmitida pelo Aedes aegypti, doença responsável por 20.000 mortes/ano no mundo. Bacillus thuringiensis var israelensis libera toxinas seletivas e eficazes (proteínas cristal) contra larvas de A. aegypti. Propõe-se um bioprocesso de baixo custo para a produção da toxina, pelo emprego de uma cepa brasileira selecionada de Bti (BR-LPB01) e de substratos de baixo custo. Farelo de soja e melaço de cana levaram a eficácia tóxica alta após fermentação em biorreator $2 \mathrm{~L}\left(\mathrm{DL}_{50}=26 \mathrm{ng} / \mathrm{mL}\right)$, valor próximo a estirpe de referência IPS82 $\left(\mathrm{DL}_{50}=17,3 \mathrm{ng} / \mathrm{mL}\right)$. 
$\mathrm{O} \mathrm{pH}$ variou entre 5,8 e 7,0 durante o período de crescimento exponencial e entre 7,0 e 8,4 durante a fase estacionária, com baixa atividade larvicida. Assim, controles de espuma e de $\mathrm{pH} \mathrm{7,0} \mathrm{foram}$ iniciados e demonstraram serem cruciais para alta atividade. Verificou-se que a fermentação deve ser interrompida após vinte horas, quando se obtém a maior atividade.

\section{REFERENCES}

Brar, S. K.; Verma, M.; Tyagi, R. D. and Valéro, J. R. (2006), Recent advances in downstream processing and formulations of Bacillus thuringiensis based biopesticides. Process Biochemistry, 41, 323-342

Codeco, C. T.; Luz, P. M. and Struchiner, C. J. (2004), Risk assessment of yellow fever urbanization in Rio de Janeiro, Brazil. Transactions of the Royal Society of Tropical Medicine and Hygiene, 98 (12), 702-710

Crickmore, N.; Bone, E. J.; Williams, J. A. and Ellar, D. J. (1995), Contribution of the individual components of the Sendotoxin crystal to the mosquitocidal activity of Bacillus thuringiensis subsp. israelensis. FEMS Microbiology Letters, 131, 249-254

Ghribi, D.; Zouari, N.; Trigui, W. and Jaoua, S. (2007), Use of sea water as salts source in starch- and soya bean-based media, for the production of Bacillus thuringiensis bioinsecticides. Process Biochemistry, 42, 374-378

Helgen, J. C.; Larson, N. J. and Anderson, R. L. (1988), Responses of Zooplankton and Chaoborus to Temephos in a Natural Pond and in the Laboratory. Archives of Environmental Contamination and Toxicology, 17, 459-471

Hsu, Y. L. and Wu, W. T. (2002), A novel approach for scaling-up a fermentation system. Journal of Invertebrate Pathology, 71, 106-114

Hynes, R. K. and Boyetchko, S. M. (2006), Research initiatives in the art and science of biopesticide formulations. Soil Biology and Biochemistry, 38, 845-849

Macoris, M. L. G.; Andrighetti, M. T.; Takaku, L.; Glasser, C. M.; Garbeloto, V. C. and Bracco, J. E. (2003), Resistance of Aedes aegypti from the state of Sao Paulo, Brazil, to organophosphates insecticides. Memórias do Instituto Oswaldo Cruz, 98 (5), $703-$ 708

Martins, F. S. V and Castiñeiras, T. M. P. P. (2005), Centro de Informação em Saúde para Viajantes, Assessed in August 27 ${ }^{\text {th }} 2008$ Inhttp://www.cives.ufrj.br/informacao/dengue/deniv.html

Obeta, J. A. N. and Okafor, N. (1984), Medium for the production of primary powder of Bacillus thuringiensis subsp. israelensis. Applied and Environmental Microbiology, 47, 863-867

Özkan, M.; F. B. Dilek; Yetis, Ü. and Özcengiz, G. (2003), Nutritional and cultural parameters influencing antidipteran delta-endotoxin production. Research in Microbiology, 154, 49-53

Pierce, R. H.; Brown, R. B.; Hardman, K. R.; Henry, M. S.; Palmer, C. L.; Miller, T. W. and Witcherman, G. (1989), Fate and Toxicity of Temephos Applied to an Intertidal mangrove Community. Journal of the American Mosquito Control Association, 4, 569-578

Pollom, T. E. V. (2003), Desenvolvimento de Bioprocessos para Produção de Biomassa e deltaendotoxina com a Cepa BR01 de Bacillus thuringiensis israelensis Berliner, 1915, visando o Controle Biológico de Aedes aegypti Linnaeus, 1762 (Diptera: Culicidae). $\mathrm{PhD}$ Thesis, Universidade Federal do Paraná, Curitiba, Brazil.

Poopathi, S. and Kumar, K. A. (2003), Novel fermentation media for production of Bacillus thuringiensis subsp. israelensis. Journal of Economic Entomology, 96, 1039-1044

Poopathi, S. and Abidha, S. (2007), Use of featherbased culture media for the production of mosquitocidal bacteria. Biological Control, 43, 49-55

Poopathi, S. and Abidha, S. (2008), Biodegradation of poultry waste for the production of mosquitocidal toxins. International Biodeterioration and Biodegradation, 62 (4), 479-482

Prabakaran G. and Balaraman, K. (2006), Development of a cost-effective medium for the large-scale production of Bacillus thuringiensis var israelensis. Biological Control, 36, 288-292

Prabakaran, G. and Hoti, S.L. (2008), Application of different downstream processing methods and their comparison for the large-scale preparation of Bacillus thuringiensis var israelensis after fermentation for mosquito control. Biologicals, 36 (6), 412-415

Prabakaran, G. and Hoti, S. L. (2008)b, Immobilization in alginate as a technique for the preservation of Bacillus thuringiensis var israelensis for long-term preservation. Journal of Microbiological Methods, 72, 91-94

Prabakaran, G.; Hoti, S. L.; Manonmani, A. M.; Balaraman, K. (2008), Coconut water as a cheap source for the production of $\delta$ endotoxin of Bacillus thuringiensis var israelensis - a mosquito control agent. Acta Tropica, 105, 35-38

Regis, L.; Monteiro, A. M.; Melo-Santos, M. A. V.; Silveira Jr, J. C.; Furtado, A. F.; Acioli, R. V.; Santos, G. M.; Nakazawa, M.; Carvalho, M. S.; Ribeiro Jr, P. J. and Souza, W. V. (2008), Developing new approaches for detecting and preventing Aedes aegypti population outbreaks: basis for surveillance, alert and control system. Memórias do Instituto Oswaldo Cruz, 103 (1), 50-59 
Regis, L.; Silva-Filha, M. H.; Nielsen-Leroux, C. and Charles, J. F. (2001), Bacteriological larvicides of dipteran disease vectors. Trends in Parasitology, 17 (8), 377-380

Report of the Epidemiological Dengue, January to November 2008 Assessed in January 08, 2009. In: http://www.combateadengue.com.br/wp-content/ uploads/2009/02/boletim-janeiro-novembro-2008.pdf.

Santa, H. S. D.; Dallasanta, O. R.; Vandenbergue, L. P. S.; Soccol, C. R. (2005), Spore production of Beuveria bassina from agro-industial residues. Brazilian Archives of Biology and Technology, 48, $51-60$

Thomas, W. E. and Eilar, D. J. (1983), Mechanism of action of Bacillus thuringiensis var israelensis insecticidal d-endotoxin. FEBS Letters, 154 (2), 362368
World Health Organization (WHO) internet site. Assessed in August 27 ${ }^{\text {th }}$, 2008. In: http://www.searo.who.int/en/Section10/Section332/ Section2270_13892.htm.

Yezza, A.; Tyagi, R. D. ; Valéro, J. R. and Surampalli, R. Y. (2006), Bioconversion of industrial wastewater and wastewater sludge into Bacillus thuringiensis var israelensis based biopesticides in pilot fermentor. Bioresource Technology, 97, 1850-1857 